Int.J. Hum. Soc. Dev. Res.

ISSN (P):2521-1439; ISSN (E):2523-4331

Volume 2, № 2, 2018. 7-18

DOI: $10.30546 / 2523-4331.2018 .2 .2 .7$

\title{
Effects of $4 c+r$ on integration in the Supply Chain Management and An application (Coordination, collaboration, cooperation, communication and relationship)
}

\section{Emine KAVAS}

Researcher, Turkey

(C) The Author(s) 2018

\begin{abstract}
The purpose of the research is to emphasize the importance of creating the required Integrated Supply Chain structure in order to reach the last users and the Members of the Supply Chain with the necessary materials in the required amounts in the required amounts, with the needed information, at the right time, at the right time and at the lowest possible cost. In the research, Supply Chain management; the effects of materials, information and monetary flow management on suppliers, producers, distributors and customers will be determined. Therefore, the coordination and integration of these flows between different businesses and within themselves; the success of the supply chain management of the enterprises will be examined. Today, rivalry is not based on companies, but on the supply chain they are in. The best way to set up and manage the supply chains will be companies that are closer to the market, know the customer's wishes and respond quickly. In the direction of the findings of the research, it is aimed to develop proposals for services of all the companies' requirement of policies in the continuously changing conditions in the globalizing economy.

Depending on the study's results, it will be able to make a better predictability contribution in the management of the operation such as the marketing area for businesses, cost studies, processing profitability ratios and supply-demand policies.
\end{abstract}

(02018.All rights reserved.

\section{ARTICLE HISTORY}

Received: $12 / 01 / 2018$

Accepted: 09/07/2018

Published online: 05/10/2018

\begin{abstract}
KEYWORDS
Supply Chain, Supply Chain Management, Integration, Business,

Coordination.
\end{abstract}




\section{Introduction}

In the Integration; in $4 \mathrm{C}+\mathrm{R}$ relation (Coordination, Collaboration, Cooperation and Communication) + (relationship); the concept of Supply Chain Management is briefly emphasized.

When we consider supply chain management, we see that in a system of suppliers, producers, suppliers and customers, it is generally about managing the flow of information, materials and money (Fox, 1999). Moreover, it can be seen that the Supply Chain Management includes methods that enable efficient integration of suppliers, producers, warehouses and suppliers to ensure that goods are distributed at the right time, in the right quantities, and in the right places, taking into account all of the costs of the system (Simchi-Levi, 2002). As it is understood from these definitions, SCM is one of the important factors in the life and profits of a company.

\section{Literature survey Supply Chain Management Notion}

"Supply chain management; covering all planning and management activities, including procurement, procurement and conversion of raw materials to product, and all logistics management activities. Besides; it also includes the coordination and cooperation of channel partners such as suppliers, intermediaries, third party service providers and customers.

Supply chain management integrates supply and demand management within and between businesses. According to the definition that LODER (Logistics Association) has made; "Supply chain management; systematic and strategic coordination of the business functions and plans of these companies to include all the companies in the chain, in order to increase the long-term performance of the supply chain and all the companies in this chain (Yurt, 2004).To sum up; integration of vital and basic business processes with the supply chain is called "supply chain management" (Cooper, Lambert, Pagh, 1997).

Lowering of costs and the creation of new value-added depends on the cooperation between supply chain partners. In the supply chain management approach, it is essential that many independent functions are integrated with the supply chain process. During this management, the "customer" is the main focus point (Stock, Lambert, 2001). Hence; the coordination of marketing functions and supply chain management activities of the businesses carry importance in terms of maximizing the overall benefit. 
Shipping, in a sense, as a category of Supply Chain is covered with Shipping and Logistics. All events related to the flow of goods throughout the Supply Chain here include transport, storage and handling of materials (material handling). These; including routing to transport vehicles, dynamic fleet management with global position system and combined transfer, sorting and storage technologies such as materials handling technologies for sorting, stocking and retrieving products.Among the products in the globalizing world market, activities like price competition, promotion, product differentiation are very similar now. Therefore; the most important issue that will create a competitive advantage is the differentiation in the supply chain and the management of logistics activities (Yurt, 2004). Because of this situation; logistics management creates a competitive advantage by increasing activity and efficiency.

\section{In the Integration of Supply Chain; Coordination, Collaboration, Communication, Cooperation and Relationships}

It explains the most important process in the integration. In today's communication age it is the head character in the establishment of the bridge between systems, along with the human factor, the direct and timely transfer of information.

\section{Communication}

It deals with the technologies used in enterprises under the communication heading. After years of 1990s, with the development of technology, computer networks started to form. As a result, the SCM phenomenon has also undergone a major shift and hand-held stocks have left their customer tracking cards in place for online orders, information-based customer tracking programs that the manufacturer and customers can follow. Thus, it is easier and faster for the companies to manage the flow of the products from their stores to the customers and / or consumers (Şahin, Demir, 2003).

Information is important for the overall performance of the supply chain, and supply chain managers decide on this basis. Information technology is made up of tools used to gain knowledge awareness. By analyzing this information and acting on this basis, it tries to improve the performance of the supply chain (Chopra, Meindl, 2007). For example, e-business technology affects the integration of production information in a supply chain, while supplier integration also affects the operational performance of the firm (Devaraj, Krajewski, Wei, 2007). There are numerous technologies for analyzing and sharing information in the supply chain; Examples include Electronic Data Interchange (EDI), Internet, Enterprise Resource Planning (ERP), Radio Frequency Identification (RFID) and Supply Chain Management / Planning (SCM / SCP) technologies. Managers must decide which 
technologies to use and how to integrate them into their own businesses and their partners' businesses. At this point in Shipping, all of the datum which is focused under the General Management has an information pool model interacted with Region and Branch Office based transferring system every day.

Mohr and Nevin (1990) connected the effectiveness of distribution channels to communication and used the "glue" metaphor to emphasize the role of communication in the development and preservation of intra-chain relationships. Communication is described by the functions of "keeping the distribution channels alive", providing information transfer, experiencing participatory decision-making processes, using power and commitment and promoting the loyalty. Variables such as in-channel satisfaction, leadership behaviors in a channel, commitment, social exchange, cooperation, control and reciprocity are also observed in research in relation to the basic concepts mentioned above. Leadership behaviors in the channel determine the co-operation in intra-channel relationships, the maintenance of mutual dependence in maintaining trust-based relationships. The literature survey suggests that leadership behaviors are not adequately examined in relation to the above variables, despite this decisive role. In the next time researches, leadership behavior in the channel should be examined more intensively.

Table.1: Comparison of old and new processes of Approaches.

\begin{tabular}{|c|c|c|}
\hline Activity & Old Applications & New Applications \\
\hline $\begin{array}{l}\text { Supplier Choice } \\
\text { (Customers) }\end{array}$ & $\begin{array}{l}\text { Different Resources, Short } \\
\text { Term Agreements }\end{array}$ & $\begin{array}{r}\text { Single resource, } \\
\text { long term strategic contracts }\end{array}$ \\
\hline Bargain & Low price & $\begin{array}{r}\text { Quality and total } \\
\text { profit price }\end{array}$ \\
\hline Delivery Program & $\begin{array}{c}\text { Responsibility of } \\
\text { Supplier(Distributor/Deliverer) }\end{array}$ & $\begin{array}{lr} & \text { Receiver and } \\
\text { Distributor } & \text { Responsibility }\end{array}$ \\
\hline Document & Official and Cumbersome & $\begin{array}{r}\text { Less document } \\
\text { electronic based } \\
\text { communication focused } \\
\text { interaction }\end{array}$ \\
\hline Packaging & Standard & $\begin{array}{r}\begin{array}{r}\text { Decision up to } \\
\text { situation }\end{array}\end{array}$ \\
\hline Inventory/Cargo & Natural Part of Work & $\begin{array}{r}\text { A handicap, } \\
\text { responsibility }\end{array}$ \\
\hline $\begin{array}{l}\text { Cargo Deliver } \\
\text { Duration To } \\
\text { Customer }\end{array}$ & $\begin{array}{l}\text { Even if it lasts long, not } \\
\text { problem }\end{array}$ & It certainly be short \\
\hline
\end{tabular}

\section{Internet}

The term "e-business" is used to describe the use of the Internet in reaching out to the objectives of supply chain integration (Muffatto, Payaro, 2004). There are many e-business categories de.pending on various kinds of trading partnerships. To these; Business to Business B2B, Business to Consumer (B2C), Consumer to Business (C2B), Consumer to Consumer (C2C), People to People (P2P), Business 
to Business (B2B) Examples are Government to Citizen (G2C), Citizen to Government (C2G), Exchange to Exchange (E2E), and Inter-Business (Organizational Unit to Organization Unit) categories given as examples. Three categories belong to E-business application as in the following (Phan, 2003):

1. Electronic Market or E-markets and Services,

2. Inter-Organizational System goods, service

3. Customer Service service, monitoring of orders and etc. things.
: Purchasing and Selling of Goods

: Ease of Inter-organization and information and cooperation flow

: Providing of Customer

\section{Barcode Technology}

It is one of the oldest examples of AIDC-based technologies. Cargo companies are indispensable. Barcode technology has application areas such as maintenance records and operations to ensure timely and accurate operation, stock control, document monitoring, upload and retrieval, production control, quality assurance. Based on commercial and industry applications, it can be argued that RFID technology is perhaps the fastest growing AIDC-based technology.

Barcode technology can effectively deal with operational inefficiencies, increase corporate productivity and empowers the firm's competitive aspect.

\section{Coordination \&Collaboration}

It is important to understand existing Supply Chain structures, restructure Supply Chain Logistics, recognize the importance of time factor, and establish a performance measurement system for Supply Chain. An integrated Supply Chain creates value for Supply Chain partners and shareholders beyond reducing costs. On the basis of integration these are included; information sharing, coordination and reorganization, organizational areas that express the sharing of costs and benefits. With the integration of Supply Chain, profitability, market share, competitive situation and company value increase. Under the success of the companies is the use of information in a proper way to manage the activities of the chain in an adaptive way.

Supply chain management is a comprehensive topic that involves many disciplines and uses some qualitative and quantitative tools. To facilitate the examination and understanding of this comprehensive topic, Johnson and Pyke have separated the Supply Chain Management to 12 for making this wide subject understood and examined easily: 
- Location

- $\quad$ Shipping and Logistics

- Inventory and Prediction

- $\quad$ Marketing and restructuring of channels

- $\quad$ Sourcing and Retailing Management

- $\quad$ Electronic Mediator environment

- $\quad$ Production Designing and Its Introduction

- $\quad$ Service and after selling service

- Reverse logistic and Environmental Subjects

- $\quad$ Outsourcing and strategic alliances

- Measurements and Incentives

- Global Subjects.

Supply chain management coordinates all logistics activities and production activities, including marketing, sales, product development, finance and information technology. This definition has increased the authority and responsibilities of the supply chain managers within the enterprises together. Managers have to plan, make, or have done and control every aspect that will create impression on production.

There are three flows in the supply chain: goods flow, monetary flow, information flow. These three flows are quite intertwined. The flow of information has the ability to act reciprocally, while the flow of goods moves one way towards the supplier to the customer. Here, the flow of goods is one way according to the supply chain elements, but in terms of the service given in the cargo, the cargo flow is two-way. The customer, i.e. the buyer (service provider), the seller (cargo company), provides two directions according to the purchaser and seller positions according to the situation they are in. In delivery of two other side the Cargo Firm is; Deliverer and the one that take the cargo is; receiver)

Actually, cargo corresponds in part to Distribution Logistics in a sense. Outbound logistics includes the physical delivery of products, also called physical distribution, to customers. Why is it important? On the supply side, the business is a customer. On the distribution side is the seller. As a buyer or seller, the business will have a significant impact on the success of the power operations. Besides, retailing/ distribution logistics include many other elements in in-house activities.

To create systems to facilitate the sharing of information between a company's value chain and its suppliers and customers, to ensure that the decisions taken are implemented in a short period of time; better reporting of yesterday, easier and better management of current day.

When collaboration and concurrent work in supply chain management is provided, Competitive advantage will be provided especially when information 
related to production planning, design and engineering, order, shipment, order status monitoring, return warnings, invoice information, contracts, supplier performance are registered and shared. Increased knowledge will let the inefficiencies in the system to be discovered and removed. At different stages of the supply chain, in coordination of activities, each step of the day-to-day processing has a special precaution. In this sense, knowledge has the feature of including other guiding elements. The profitability of each partner will also increase as the share of chain partners increases from the supplier to the final consumer. A big textile firm will be able to supply, produce and present to customers as soon as possible the color of the fabric desired by the retailer, when the customer turns the color and model preferences into wisdom and also shareable information.

There are a few reasons why supply chain management has attracted so much attention in recent years. Most of the managers now realize that even the single member of the chain can affect the profitability of all other members. Firms are increasingly looking to compete with other supply chains as a single firm rather than competing with other companies alone as a member of a Supply Chain. Firms can also achieve better coordination in their own suppliers and customers as well as in increasing their efficiency in their own activities.

Successful processing of the Supply Chain depends on chain integration and management. Successful coordination of the partners providing the chain integrity, the suppliers, the parts of each company, the third parties of the carriers and the information systems of the most important chain operation will eventually lead to a successful chain operation. For this purpose, the entire chain must work together in coordination. They need to know the requirements of the market and the market very well, conceptualize the idea of competition very well, and identify any kind of information that will coordinate the activities of their trading partners. This kind of integrity requires good use of technology. Market demand must use all kinds of technology so that customer expectations can understand exchange of information between institutions. The necessary determinations should be made to increase the immediate detection and process capability of a yield reduction (which may result from suppliers, production centers, warehouses, customers and demand) that may occur in the chain integrity. For this reason, Supply Chain integration means coordinated integration of all the factors in the Supply Chain. The cost of poor coordination can be unexpectedly high. Correction of errors will increase the cost of every change made to the name, due to the inefficient production and storage resources and high shipping and inventory costs.

The SCM strategy differs from the firm-level strategies because the firmlevel strategies require coordination of internal processes; The SCM strategy requires coordination between all the processes involved in the supply chain. 
Therefore, the achievement of the objectives of the supply chain management strategy (product development, income increase, reduction of working capital and fixed capital amount, reduction of operating costs, increase of market share, customer satisfaction etc.) depend on coordination and commitment between the firms (Christensen, 2000).

Customer-aspected SCM practices aim to reduce both operational uncertainty (which product, where, when, how much, what price and quality) and structural uncertainty (change in customer requirements). Preventive maintenance, implementation of various improvement programs and production techniques, etc. intrinsic supply chain practices aim to reduce operational and structural uncertainty at firm level. Supplier-oriented SCM applications are; aims to reduce operational uncertainty by aligning production schedules and techniques by reducing structural uncertainty by combining firms' unique capabilities and by sharing knowledge about the market or the customer. As a result, it can be argued that SCM practices at a certain level will differentiate firms from competing supply chains and provide sustainable competitive advantage.

\section{Cooperation}

Center- Regions - Technical Centers - Inter-branches management encapsulates internal and external customers.Common benefit in SCM ; As a result of the cooperation between the enterprises, it is possible to create a preferred product / service and necessary service structure in terms of quality, price. The most important benefit of cooperation in this regard is that they must combine the information in the hands of the parties. Branch; customer needs and criticism information; information on the market and design possibilities of the enterprise; material, price and quality information. This returns to all parties as a cost advantage.

\section{Integration}

Integration can be succeeded via coordination of experts (Grant, 1996). One of the coordination mechanisms that can be used in the coordination of experts is team work (team problem solving and decision making). Teamwork is a formless and communication intensive integration mechanism. This type of integration is particularly influential due to the intensity of communication and information transfer in unusual complex and important missions (Grant, 1996).

\section{Relationship}

Leadership and strategy in supply chain management show an interaction that supports each other. The predictions of the strategies have a positive effect on the establishment of the leadership authority. Consistent development of leadership 
is positively impacting on the implementation and monitoring of strategies.Besides this, organizations are increasingly interested in the "human" dimension in the management of a fully integrated supply chain. Often the information and communication technologies required for the supply chain are already available and can be set up easily and quickly, with the exception of some minor setbacks. Managing mutual relationship and trust between different people in organizations is the most challenging aspect of supply chain management. When choosing among the qualifying businesses that will respond to the need for cooperation, the points to be cared are these:

- Management skill

- Personnel skill

- Process and technological skill potential

-Total quality management philosophy - Production planning and control systems

- Finance sustainability and sourcing finding skill

The anticipated performance of co-operation is achieved or, if it goes above, the parties are satisfied. The term "successful co-operation" does not only refer to co-operation that implements performance expectations, but also to co-operation that governs disagreements. Problem solving has key importance in the continuity of collaboration.

\section{Method}

\section{Purpose and Extent of the Research}

Integration explains the integration and the working in adaptation of all systems. According to the research model, company performance criteria as an indicator of being integrated. According to this situation, the level of company's integration will be measured. A questionnaire was applied to customers and employees to evaluate the company's performance. Then, the methodology of research was put forward by statistical analyses.

\section{Problem}

Cargo companies are failing to balance supply and demand. Rakip cargo companies sell services with variable and intense discounts on cargo prices. Problems with time concept in the main line between regions, cargo diversity differs from regional techniques to branches and customer delivery from time to time is difficult (with dimensions / volume). 
Internal and external information flows are not very healthy. Considering the problems, the integration level of the company is suspicious.

\section{Research Methodology}

As a research method in the study, sampling-based examination method was determined. The research was performed by questionnaire method. The desired result is the factors that affect the integration of the business in Supply Chain Management. Basic variances have been determined. The survey form prepared related to this subject has been filled in by a specific sample.

\section{Result and suggestions}

The firm could not provide enough level of integration.

- Being able to cope with uncertainty with the ability to be fast and flexible can compete against cheap labor. Improvements are needed in the distribution processes of branches in order to be flexible and flexible.

- Integration of information technology to customer, service and distribution

Branches, transfer centers (operations unit), the General Directorate of integration and strategic partnerships is the biggest factor in the human factor. Integration training exercises regularly should be provided throughout Turkey within the firm and outside, horizontal-vertical positioning of the bi-directional flow of information must be provided.

At every point of importance and effect of customer perception must always be taken into consideration in coordination within and outside the business. In addition to this, it should be kept in mind that the internal customers, who represent the business, should act with the awareness that the perceptions are influential at various points. Internal customer satisfaction is important in this context.

\section{Dealing with Vagueness}

Measuring of Vagueness

Difference between predicted and realized demand - correct measurement of actual demand

\section{Decision making under uncertainty}

To provide an "optimal" number of delivery services by considering the costs, not as much as expected, but with the probabilities of more or less likely to occur, by vehicle or pedestrian courier; service must be provided. If I reached 
under target, I will lose $\mathrm{x}$ TL, then I reached out above the target I will lose y TL. What should I aim for? How should I use pedestrian and distribution vehicles? Responsive pooling: Estimating aggregate demand is easier than estimating the demand for individual services, or individual distribution points. In-branch customer distribution points, grouping in the address based area, pedestrian delivery1, pedestrian delivery 2 and vehicle courier directing should be provided ... Facility pooling - Storage; in-branch transfer cargo should be grouped ... (file and big cargos) Regular rings should be located in branches from each region transfer center. This will provide faster and better quality delivery.

Some practices are suggested as ways of dealing with uncertainty. These are Rapid Reaction; the aim should be to arrange seasonally planned branch rods and time at the lowest distribution points (branches) by pulling down the supply time as much as possible, therefore ensuring that in-branch distribution starts without any delay.

In both distribution and customer acquiring aspected proposals; Collaboration between regional techniques and cooperation between branches is important in the next step (at the same time, the bidders will bid in their own fields, which is the factor in intra-branch customer studies). Desired Response: Coordinating distribution channels according to the demand during the season by pulling down the supply time is important for a punctual delivery. Pricing strategies must be implemented in the seasons.

\section{Demand Vagueness and Flexible Capacity}

While making capacity decisions it is quite difficult to make demand prediction because it is about long time after the situation. One way to solve this problem is to gain flexibility (in the sense of time and place) to each transfer center and then to the branch in all kinds of distributions. However, the flexibility is expensive. For every kind of market, how can we response without increasing the costs too much? These and similar questions should be answered.

\section{Disclosure statement}

No potential conflict of interest was reported by the author.

\section{Contact Information}

E-mail: pskapo@hotmail.com 


\section{References and notes:}

Atalay. D. (2018) The management of information in education management by using share point programme. International Journal of Humanities and Social Development Research. Vol 2(1), 2018.Baku, Azerbaijan

Bajrami, D., Reci, T., \& Iseni, A. (2016). Public Relations, Mass Media and Informal Education. European Scientific Journal, ESJ, 12(19).

Chopra, S. \& Meindl, P. (2007). Supply Chain Management: Strategy, Planning, and Operation, New Jersey, Pearson Prentice Hall.

Christensen, C.M. (2000., European Journal of Purchasing \& Supply Management (6)2, pp.105-116.

Cooper, M.C.,Lambert, D.M. \& Pagh, J.D. (1997). Supply Chain Management: More Than a new Name for Logistics, The International Journal of Logistics Management, (8)pp. 11-14

Devaraj, S., Krajewski, L., Wei, J.C. (2007). Impact of e-Business Technologies on Operational Performance: The Role of Production Information Integration in the Supply Chain, Journal of Operations Management, 25, pp.12-29.

Fox, S. (1999), Digital Market, Inc. Stanford Global Supply Chain Management Forum Case, SGSCMF-005-1999.

Grant, R.M. (1996), Toward a knowledge-based theory of the firm, Strategic Management Journal, First published: Winter 1996 https://doi.org/10.1002/smj.4250171110

Mohr, J.\& Nevin, J. (1990). Communication Strategies in Marketing Channels: A Theoretical Perspective, Journal of Marketing,54, pp.36-51.

Muffatto, M.\&Payaro, A. (2004). Integration of Web-based Procurement and Fulfillment: A Comparison of Case Studies, International Journal of Information Management, 24,pp. 296-310.

Phan, D.D. (2003). E-Business Development for Competitive Advantages: A Case Study, Information \& Management, 40, pp.582-600.

Simchi-Levi, D., Kaminsky, P.\& Simchi-Levi, E. (2002).Designing and Managing the Supply Chain, New York, McGraw-Hill.

Stock, J.R., Lambert, D.M. (2001).Strategic Logistics Management. 4th Edition, New York, McGraw Hill

Şahin, A. \&Demir, M.H. (2003), The Effects of Developments in Information Technologies on Logistics Management: A Theoretical Analysis of Supply Chain Orientation, Süleyman Demirel University Faculty of economics and administrative sciences Journal, (8) 3, pp.31-40

Yurt, Ö. (2004), Turkey factor- Confidence in Logistics Outsourcing Practice, (Unpublished master's thesis). Ankara University / Institute of Social Sciences, Ankara.

Zubov, D., SHIKOSKA, U. R., ZHARIKOV, E., \& Iseni, A. (2015). Science and University Education: One Subjective Point of View about Foreign Teachers. ANGLISTICUM. Journal of the Association for Anglo-American Studies, 1(2), pp.31-36. 